\title{
Correlations among Perceived Autonomy Support, Intrinsic Motivation, and Learning Outcomes in an Intensive Foreign Language Program
}

\author{
Erin N. O’Reilly \\ Faculty Development Division, Defense Language Institute Foreign Language Center, Monterey, California, United \\ States of America
}

\begin{abstract}
This study assesses how learners' perceptions of classroom autonomy correlate to intrinsic motivation and learning outcomes as measured by grade point average (GPA); analysis of the data shows a positive correlation among the variables and supports the argument that the psychosocial variable of perceived autonomy support can be used to maintain intrinsic motivation and enhance learning outcomes over time. Adult learners $(n=77)$ enrolled in an eight-week, intensive academic language program completed two survey instruments during the first and seventh week of the program. Correlational analyses determined that greater perceptions of learners' autonomy support were strongly correlated to higher levels of intrinsic motivation and moderately correlated to GPA. Perceived autonomy support accounted for $9 \%$ of the variance in learners' GPA.
\end{abstract}

Index Terms —self-determination theory, perceived autonomy, language learner motivation

\section{INTRODUCTION}

One glance at the learning objectives for a typical semester-long foreign language course can quickly leave a teacher feeling overwhelmed. Each year, highly motivated adult language learners enroll in intensive, academic language programs with the expectation of developing proficiency. For these programs which pack two semesters of material into the improbable span of eight weeks, the perfunctory response from a course design perspective is to employ a lockstep approach to content delivery around the learning objectives, ensuring maximum productivity in every 60-90 minute lesson. As language teachers know from first-hand experience, learning a second language (L2) as an adult is a complex process, and cognitive ability alone is insufficient to guarantee or predict proficiency development. For language learners, affective variables are as critical as aptitude when predicting language learning achievement (Gardner, 1985; Scovel, 2000).

Of the affective variables studied in the field of second language acquisition (SLA), motivation plays a critical role in the rate and success of adult L2 acquisition (e.g., Dornyei, 1998; Gardner, 2010; Reeve, 2006). Motivation influences the amount of effort students invest in language learning (Gardner, 1985; Oxford, 1989). Whether their proficiency goals are academic, professional, or personal, learners' motivation serves as the catalyst to begin studying a language and to sustain those efforts over time. As such, examining factors that influence motivation is crucial to help understand the language learning process. Practitioners should plan for learners' motivation and those factors influencing motivation. By harnessing motivation's power, the teacher is in a position to compel learners to work persistently through whatever course demands may come.

Motivation is a complex construct understood through various perspectives. Precisely because of the effort required to learn a language, Dornyei (2003) advocated a process-oriented approach when studying motivation in language learners, one that can describe the inevitable changes in motivation that come with the individual's stage in the learning process and the goals set ahead of him or her. At its base level, motivation is a neurobiological function, which results from how an individual appraises a set of stimuli as either being positive and rewording or negative in relation to a specific goal (Schumann \& Wood, 2008). Examples of stimuli include teacher feedback (e.g., "Great job!" or "I just taught this. Weren't you listening?"), task success (e.g., finishing a project or presentation), grades, and social interactions (e.g., group work with friends or group work with strangers). A learner who appraises a situation positively will continue to work towards achieving his or her goal. Conversely, the learner will avoid target language stimuli which he or she appraises as negative (Schumann \& Wood, 2008). Continued positive appraisals of stimuli over an extended period sustain learners' motivation levels and eventually lead to successful foreign language acquisition.

The current study uses the Self-Determination Theory (SDT) as a framework to understand motivation and its role in an individual's participation in an activity or task (Deci \& Ryan, 1985, 2000, 2008). Deci and Ryan (1985, 2000) posited that humans have three basic needs when pursuing an activity, and the SDT framework is based on the degree to which each individual's basic needs are met in a given context when carrying out the activity. These three basic needs are: feelings of competency, feelings of relatedness (i.e., belonging), and perceived autonomy support (i.e, perceived freedom of choice about learning tasks) (Deci \& Ryan, 2000). These three needs fall on a continuum and interact to 
influence an individual's level of motivation (Vandergrift, 2005). Changes in any of these basic needs can result in a change in the level of self-determined motivation an individual experiences.

The SDT has three main categories of motivation which describe how self-determined, or freely chosen, an individual's actions are. These categories are, in order from least self-determined to most self-determined: amotivation, extrinsic motivation, and intrinsic motivation (Noels, Pelletier, Clement, \& Vallerand, 2003). Intrinsic motivation is the most self-determined form of motivation and describes activities or goals that are chosen freely by the individual because they are "interesting and fun to do" (Noels et al., 2003, p. 101). These individuals experience a sense of full volition during task performance.

The SDT framework applies to a wide range of life activities (Deci \& Ryan, 2008), and was extended to the field of adult L2 learning by Noels, Clement, and Pelletier (2001) in a study of 159 adult English speakers learning French, validating that language learner motivation can be assessed using the intrinsic motivation subtypes delineated by Deci and Ryan (2000). The SDT has since been used successfully in various studies involving language learning (e.g., Noels, 2009; Noels et al, 2003; Vandergrift, 2005).

Of the three universal needs in SDT, autonomy support is the basic need that directly influences student motivation. Contexts that support perceived autonomy, or foster perceived control, tend to maintain or increase intrinsic motivation, whereas contexts that individuals perceive as controlling weaken intrinsic motivation (Black \& Deci, 2000). More specifically, scholars argue that student perceptions of autonomy supportive classroom environments affect individual learner motivation (Noels, Clement, \& Pelletier, 1999; Noels et al., 2003; Reeve, 2006). Indeed, Reeve (2006) proposed a dialectic relationship wherein the student's long-term motivational growth depends upon a learning environment that allows him or her freedom of choice when pursing a learning activity or goal.

Within the field of SLA, researchers have examined the role of perceived autonomy support in adult language learners. Noels et al. (1999) found that students who perceived their teachers as controlling in the classroom and critical with feedback reported lower levels of intrinsic motivation. In a similar study examining how various motivational subtypes correlate to teachers' communication styles, Noels et al., (2003) found a positive correlation between learners' intrinsic motivation and their perceptions of teachers who were autonomy-supportive. Conversely, students with a decreased sense of control over their learning environment experienced decreased levels of intrinsic motivation. This highlights the importance of students' perceived autonomy in maintaining more self-determined forms of motivation, as well as how external variables, in this case the teachers, might influence intrinsic motivation. One design limitation to the study was that it measured learners' perceptions and motivational orientations at one point in time; as such, the researchers called for a longitudinal research methodology to examine the interaction of variables over time (Noels et al, 2003). The present study extends this research using a longitudinal design measuring learners' intrinsic motivation both at the beginning and end of the course.

Beyond influencing intrinsic motivation, autonomy support can also impact learner outcomes. In an experiment designed to extend the SDT framework to an educational context, Boggiano, Flink, Shields, Seelbach, and Barrett (1993) measured the correlation between performance outcomes and freedom of choice on analytical tasks with adult learners. The researchers' findings, while not specific to the foreign language context, identified that autonomy supportive learning environments act as a foundational predictor variable between levels of motivation and learning outcomes.

Intensive language courses typically adhere to set curricula, with few opportunities for students to guide lessons. When analyzed from the SDT perspective, this highlights the need to examine perceived autonomy support as a factor influencing intrinsic motivation over time as well as learning outcomes in the intensive foreign language classroom.

\section{PURPOSE}

External factors can threaten learners' intrinsic motivation. This idea conforms to Black and Deci's (2000) finding using the SDT framework that autonomy-supportive learning contexts can maintain and enhance learners' intrinsic motivation, while learning environments that students perceive as controlling undermine intrinsic motivation. Students in autonomy-supportive environments experience greater levels of enjoyment and better academic performance. The basic need of autonomy either fosters or undermines students' intrinsic motivation, which directly correlates to outcomes.

Many scholars have argued that learner autonomy supports intrinsic motivation and outcomes. The present study extends this argument to the intensive, academic foreign language context. The purpose of this study was to analyze the relationship among learners' perceptions of autonomy support, changes in intrinsic motivation over time, and proficiency outcomes in adult foreign language learners $(N=77)$ enrolled in an intensive, academic foreign language program. The study focused on the following research question:

$R Q$. What are the correlations among perceived classroom autonomy support, students' intrinsic motivation (T1) (T2), and language acquisition among adult foreign language learners enrolled in an intensive, academic foreign language program?

The answer should provide meaningful insight to teachers and administrators concerned with maintaining learners' motivation in intensive language programs.

\section{METHOD}




\section{A. Participants}

The setting of the study was a graduate college in the United States known for specializing in foreign language education, interpretation, and translation. Participation was voluntary and all students enrolled in the program were eligible to take part in the study. The study consisted of 77 adult learners enrolled in a summer intensive, academic foreign language program. Ages ranged from 18 to 45; the mean was approximately 25 years (SD 5.64). Participants reported demographic data, including: age, gender, and language of study. Of the participants in the sample, 33 (42.9\%) were female and $42(54.5 \%)$ were male.

Students came from around the United States and enrolled in the Arabic, Chinese-Mandarin, Russian, French, and Spanish programs at the beginning through the advanced levels according to the American Council for the Teaching of Foreign Languages scale. The average class size was 10 students. In this academic setting, students attended class five days a week, for five hours of academic instruction daily, followed by approximately 4 hours of assigned homework and self-study outside of class. The 8-week course consisted of 180 hours of academic instruction with curricula focusing on proficiency development. The setting of the current study was similar to intensive academic language programs offered at other college-level educational institutions.

\section{B. Materials}

The instruments included in the current study are widely used in educational psychology. They were adapted for the academic foreign language context. The following is a description of the scales along with their Chronbach's alpha of internal consistency.

\section{Intrinsic Motivation}

Intrinsic motivation was measured using the standard 7-item Intrinsic Motivation Inventory (IMI) interest/enjoyment subscale designed to examine the participant's self-perception of the interest/enjoyment of a given task (SelfDetermination Theory, 2008). The interest/enjoyment subscale is considered a self-measure of intrinsic motivation ( $\alpha$ $=.78$ ) (McAuley, Duncan, \& Tammen, 1989). The scale has been shown to maintain its validity and reliability when substituting the chosen activity for the word task (Self-Determination Theory, 2008). As such, the word task was changed to learning my language. Items were rated by range on a 6-point scale ranging from 1 (not at all true) to 6 (very true). Sample items from the index included, "I feel like I am doing what I want to do while I am working on learning my language," and "I feel pressured while learning my language."

\section{Autonomy Support}

Perceived autonomy support was measured using the Learning Climate Questionnaire (LCQ) $(\alpha=.93)(B l a c k \&$ Deci, 2000) designed for use with college students to measure participants' perceptions of instructor autonomy support. The LCQ is a 15-item Likert-type instrument, with items rated on a 7-point scale ranging from 1 (strongly disagree) to 7 (strongly agree). Sample items from the index included, "I feel that my instructors provide me choices and options" and "I don't feel very good about the way my instructors talk to me."

\section{Learning Outcomes}

The program monitored student progress closely, with learners receiving weekly grade reports. Participants selfreported their GPA at week seven to measure language acquisition.

\section{Procedure}

Questionnaires were distributed during class at the end of the first week (T1) and again during week seven (T2). The T1 questionnaire consisted of the IMI as well as background information on language of study, age, and gender. This initial questionnaire served as a baseline measurement of intrinsic motivation in support of a process-oriented approach to to capture motivational changes over time (Dornyei, 2003). The T2 questionnaire consisted of the IMI and LCQ, to measure intrinsic motivation (T2) and perceived autonomy support, respectively. Surveys were coded to ensure participant anonymity. Participants had the option to opt out at any time.

Data were analyzed using SPSS 16.0. All data were inputted using double entry. Stepwise deletion was used for missing data points. A partial correlation analysis was used to control for the confounding variables of age and gender. In order to run the partial correlation analyses for the control variables of age and gender, the primary variables of intrinsic motivation (T1) (T2), perceived autonomy support, and GPA were converted into ranked variables. A Spearman correlation can be considered as a Pearson correlation between ranked variables (Howell, 1997).

\section{RESULTS}

\section{A. Reliability}

Means and standard deviations were calculated for each of the primary variables and are shown in Table 1, which shows that item means (standard deviations are bracketed) for intrinsic motivation ranged from 5.31 (1.10) to 5.24 (0.98) for (T1) and (T2), respectively, to 5.08 (1.83) for perceived autonomy support. 
TABLE I

MEANS AND STANDARD DEVIATIONS FOR PRIMARY MEASURED VARIABLES

\begin{tabular}{llll}
\hline Primary Variables & $N$ & Mean & Std. Deviation \\
Intrinsic Motivation T1 & 76 & 5.31 & 1.10 \\
Perceived Autonomy Support & 77 & 5.08 & 1.83 \\
Intrinsic Motivation T2 & 77 & 5.24 & 0.98 \\
\hline
\end{tabular}

Chronbach's alpha for each of the surveys and subscales used were acceptable $(\alpha>0.70)$ (Nunnaly \& Bernstein, 1994). The IMI interest/enjoyment subscale had a consistency of $\alpha=0.75$ (T1) and $\alpha=0.76$ (T2). The LCQ had a consistency of $\alpha=.98$.

\section{B. Correlations Among Variables}

To assess the relationship among perceived autonomy support, intrinsic motivation (T1) (T2), and learning outcomes, a Spearman's rho correlation matrix was conducted between each of the variables. The results are shown in Table 2 .

Perceived autonomy support had a moderate positive correlation with intrinsic motivation $(\mathrm{T} 1)(\mathrm{r}=.249, \mathrm{p}<.05)$, and a strong positive correlation with intrinsic motivation $(\mathrm{T} 2)(\mathrm{r}=.522, \mathrm{p}<.001)$ and GPA $(\mathrm{r}=.33, \mathrm{p}<.01)$. Participants who self-reported more perceived autonomy support from their teachers tended to report higher levels of intrinsic motivation throughout the course and higher GPAs at the end of the course.

TABLE II.

SPEARMAN'S RHO CORRELATIONS AMONG PRIMARY RESEARCH VARIABLES

\begin{tabular}{|c|c|c|c|}
\hline & Intrinsic Motivation (T1) & Intrinsic Motivation (T2) & Perceived Autonomy Support \\
\hline Intrinsic Motivation (T1) & - & - & - \\
\hline \multicolumn{4}{|l|}{$N$} \\
\hline Intrinsic Motivation (T2) & $.596^{* * *}$ & - & - \\
\hline$N$ & 76 & & \\
\hline Perceived Autonomy Support & $.249^{*}$ & $.522^{* * *}$ & - \\
\hline$N$ & 76 & 77 & \\
\hline GPA & .123 & $.273^{*}$ & $.333^{* *}$ \\
\hline$N$ & 64 & 64 & 64 \\
\hline
\end{tabular}

Further, while intrinsic motivation (T1) had no significant correlation to GPA, intrinsic motivation (T2) did have a moderate positive correlation to GPA $(\mathrm{r}=.274, \mathrm{p}<.01)$. This indicates that learners' level of intrinsic motivation at the beginning of the course was unrelated to learning outcomes, while intrinsic motivation at the end of the course was related.

In addition to investigating the correlations among perceived autonomy support, intrinsic motivation, and foreign language acquisition, the current study also investigated the relative effects of the primary variables on language acquisition as measured by GPA. The stepwise regression did show that perceived autonomy support was found to have moderate variability on participants' GPA $(\beta=.29, \mathrm{p}<.05)$. The overall regression was $R^{2}=.09$; these findings indicate that perceived autonomy support accounted for approximately $9 \%$ of the variability in participants' GPAs. This finding was consistent with other findings in the literature on autonomy support and academic outcomes (Boggiano et al., 1993).

The partial correlation analysis used to control for the confounding variables of age and gender and resulted in no statistically significant differences to the $p$ values that emerged from the Spearman's rho correlations. In terms of significance in this context, controlling for the confounding variables of age and gender did not significantly alter the correlations among the primary variables of intrinsic motivation (T1) (T2), autonomy support, and language acquisition.

\section{IMPLiCATIONS AND GENERAL DiSCUSSION}

The current study examined the role of perceived autonomy support in an intensive, academic foreign language program. The primary research question focused on the correlations among perceived autonomy support, intrinsic motivation, and language acquisition. The results indicate the existence of a positive correlation among the variables. Additionally, stepwise regression indicates that the variable perceived autonomy support accounts for $9 \%$ of the variability in participants' GPAs. In the study's context, participants who enjoyed greater perceived autonomy supportive learning environments also tended to have better academic learning outcomes.

The results suggest that perceived autonomy support is linked with intrinsic motivation and learning outcomes in a manner consistent with previous research (Deci \& Ryan 1985; Noels et al., 2001). The study further supports the idea that perceived autonomy support is a psychosocial variable which can be harnessed to enhance learners' motivation (cf. Noels, 2003), as well as learning outcomes (Bogiano et al, 1993).

Intrinsic motivation (T1) and perceived autonomy support shared a significant, although weak, correlation $(r=.249$, $p<.05)$. The possibility exists that during the first week in the program changes in participants' motivation levels had already begun, and is a design limitation in the present study. While causation cannot be determined, the correlation 
between intrinsic motivation and perceived autonomy support this early in the course indicates the value of future research with these two variables.

The positive correlation between intrinsic motivation (T2) and GPA $(r=.273, p<.05)$ suggests changes in motivation orientation are correlated to learner outcomes (Dornyei, 1998; Scovel, 2000). In the current study, participants with higher levels of self-reported intrinsic motivation at week seven also self-reported higher GPAs.

The limitations in this study are those inherent in studies relying on self-reported data. There were three readily apparent confounding variables which were not examined: language level, language, and clustering. First, the population size was not large enough to restrict participants by level of language learner (e.g., beginner, intermediate, advanced). This weakened the internal validity of the research. Similarly, the statistical analysis did not control for target language (i.e., the foreign language the participant was studying in the program). It was assumed that adults experience foreign language learning in an intensive academic setting in a similar manner between languages. Another limitation to the current design was the potential impact of clustering of students within classes. A particular class may have shared a learning experience that significantly impacted their responses to this research topic. These three variables should not be considered inclusive of all possible confounding variables which, for practical purposes, were outside the scope of the present study. Finally, the study only focused on learners' perspectives. Extending the research to include teachers' experiences and classroom practice would give a better idea of how perceived autonomy support, intrinsic motivation, and proficiency development interact.

\section{CONCLUSION}

Identifying and understanding affective variables in adult foreign language learners is of import for educators and program administrators involved in curriculum design and teaching methodology. This study strengthens the argument that perceived autonomy support, intrinsic motivation, and learner outcomes are correlated. The results suggest that perceived autonomy support is a psychosocial variable that can impact learner outcomes.

Course outcomes tend to dictate many classroom practices; however, factors influencing motivation and perceived autonomy support also need consideration. Practitioners can foster an autonomy supportive classroom climate in multiple ways. Deci and Ryan (1985) offer suggestions to support learners' feelings of autonomy. Teachers can give learners a choice over classroom and homework activities (e.g, a report or a presentation), or by offering learners a choice about due dates (e.g., before the final or after). Other options can include soliciting topics and ideas for activities from the learners directly, co-constructing a syllabus based on learners' needs and interests. The teacher is limited only in his or her creative abilities to identify occasions for learners to exercise freedom of choice.

\section{ACKNOWLEDGEMENT}

The author wishes to thank Dr. Alexandru Spatariu, Dr. Gordon Jackson, and Dr. Seamus Rogan.

\section{REFERENCES}

[1] Black, A. E., \& Deci, E. L. (2000). The effects of instructors' autonomy support and students' autonomous motivation on learning organic chemistry: A self-determination theory perspective. Science Education 84.6, 740-756. doi:10.1002/1098237X(200011) 84:6<740::AID-SCE4>3.0.CO;2-3

[2] Boggiano, A. K., Flink, C., Shields, A., Seelbach, A., \& Barrett, M. (1993). Use of techniques promoting students' selfdetermination: Effects on students' analytic problem-solving skills. Motivation and Emotion 17.4, 319-336. doi:10.1007/BF00992323.

[3] Deci, E., \& Ryan, R. (1985). Intrinsic motivation and self-determination in human behavior. New York, NY: Plenum.

[4] Deci, E., \& Ryan, R. (2000). The "what" and "why" of goal pursuits: Human needs and the self-determination of behavior. Psychological Inquiry, 11, 227-268. doi:10.1207/S15327965PLI1104_01.

[5] Deci, E. \& Ryan, R. (2008). Self-determination theory: A macrotheory of human motivation, development and health. Canadian Psychology, 49, 182-185. doi:10.1037/a0012801.

[6] Dörnyei, Z. (1998). Motivation in second and foreign language learning. Language Teaching, 31, 117-135. doi:10.1017/S026144480001315X.

[7] Dörnyei, Z. (2003). Attitudes, orientations, and motivations in language learning: Advances in theory, research, and applications. In Z. Dornyei (ed.), Attitudes, orientations, and motivations in language learning (vol. 53). Malden, MA: Blackwell Publishing, 3-32.

[8] Gardner, R. (1985). Social psychology and second language learning: The role of attitudes and motivation. London, England: Arnold.

[9] Gardner, R. (2010). Motivation and second language acquisition: The socio-educational model. New York, NY: Peter Lang.

[10] Howell, D. C. (1997). Statistical methods for psychology ( $4^{\text {th }}$ ed.). Belmont, CA: Duxbury Press.

[11] McAuley, E., Duncan, T., \& Tammen, V. V. (1989). Psychometric properties of the Intrinsic Motivation Inventory in a competitive sport setting: A confirmatory factor analysis. Research Quarterly for Exercise and Sport, 60.1, 48-58.

[12] Noels, K.A. (2009). The internalization of language learning into the self and social identity. In Z. Dornyei \& E. Ushioda (eds.), Motivation, language identity and the L2 self. Tonawanda, NY: Multilingual Matters, 295-311.

[13] Noels, K. A., Clement, R., \& Pelletier, L. G. (1999). Perceptions of teachers' communicative style and students' intrinsic and extrinsic motivation. Modern Language Journal, 83, 23-34. doi:10.1111/0026-7902.00003. 
[14] Noels, K., Clement, R., \& Pelletier, L. G. (2001). Intrinsic, extrinsic, and integrative orientations of French Canadian learners of English. Canadian Modern Language Review, 57, 424-440. doi:10.3138/cmlr.57.3.424.

[15] Noels, K., Pelletier, L., Clement, R., \& Vallerand, R. (2003). Why are you learning a second language? Motivational orientations and self-determination theory. In Z. Dornyei (ed.), Attitudes, orientations, and motivations in language learning (vol. 53). Malden, MA: Blackwell Publishing, 33-63.

[16] Nunnaly, J. C., \& Berstein, I. H. (1994). Psychometric theory ( $3^{\text {rd }}$ ed.). New York, NY: McGraw-Hill.

[17] Oxford, R. (1989). Use of language learning strategies: A synthesis of studies with implication for strategy training. System, 17.2, 235-247. doi:10.1016/0346-251X(89)90036-5.

[18] Reeve, J. (2006). Teachers as facilitators: What autonomy-supportive teachers do and why their students benefit. The Elementary School Journal, 106.3, 225-236. doi:10.1086/501484.

[19] Schumann, J. H., \& Wood, L. A. (2008). The neurobiology of motivation. In J. H. Schumann, S. E. Crowell, N. E. Jones, N. Lee, S. A. Schuchert, \& L. A. Wood (eds.), The neurobiology of learning: Perspectives from second language acquisition. Mahwah, NJ: Lawrence Erlbaum, Inc., 23-42.

[20] Scovel, T. (2000). Learning new languages: A guide to second language acquisition. Boston, MA: Heinle \& Heinle.

[21] Self-Determination Theory. (2008). Intrinsic Motivation Inventory. http://www.selfdeterminationtheory.org/questionnaires/10questionnaires/82Self-study (accessed 18/04/2012).

[22] Vandergrift, L. (2005). Relationships among motivation orientations, metacognitive awareness and proficiency in L2 listening. Applied Linguistics, 26.1, 70-89. doi:10.1093/applin/amh039.

Erin N. O'Reilly received her PhD in English as a Second Language from Northcentral University, Arizona, U.S.A, in 2012. She is currently an associate professor at the Defense Language Institute Foreign Language Center in Monterey, California, where she works in the Faculty Development Division. Dr. O'Reilly's research interests include: learner strategies, learner autonomy, and learner variables. 